\title{
AI and SWARM
}

\section{Evolutionary Approach to Emergent Intelligence}

\section{Hitoshi Iba}

Information and Communication Engineering School of Information Science and Technology The University of Tokyo, Japan 
CRC Press

Taylor \& Francis Group

6000 Broken Sound Parkway NW, Suite 300

Boca Raton, FL 33487-2742

(C) 2020 by Taylor \& Francis Group, LLC

CRC Press is an imprint of Taylor \& Francis Group, an Informa business

No claim to original U.S. Government works

Printed on acid-free paper

Version Date: 20190725

International Standard Book Number-13: 978-0-367-13631-4 (Hardback)

This book contains information obtained from authentic and highly regarded sources. Reasonable efforts have been made to publish reliable data and information, but the author and publisher cannot assume responsibility for the validity of all materials or the consequences of their use. The authors and publishers have attempted to trace the copyright holders of all material reproduced in this publication and apologize to copyright holders if permission to publish in this form has not been obtained. If any copyright material has not been acknowledged please write and let us know so we may rectify in any future reprint.

Except as permitted under U.S. Copyright Law, no part of this book may be reprinted, reproduced, transmitted, or utilized in any form by any electronic, mechanical, or other means, now known or hereafter invented, including photocopying, microfilming, and recording, or in any information storage or retrieval system, without written permission from the publishers.

For permission to photocopy or use material electronically from this work, please access www.copyright.com (http://www.copyright.com/) or contact the Copyright Clearance Center, Inc. (CCC), 222 Rosewood Drive, Danvers, MA 01923, 978-750-8400. CCC is a not-for-profit organization that provides licenses and registration for a variety of users. For organizations that have been granted a photocopy license by the CCC, a separate system of payment has been arranged.

Trademark Notice: Product or corporate names may be trademarks or registered trademarks, and are used only for identification and explanation without intent to infringe.

$$
\text { Library of Congress Cataloging-in-Publication Data }
$$

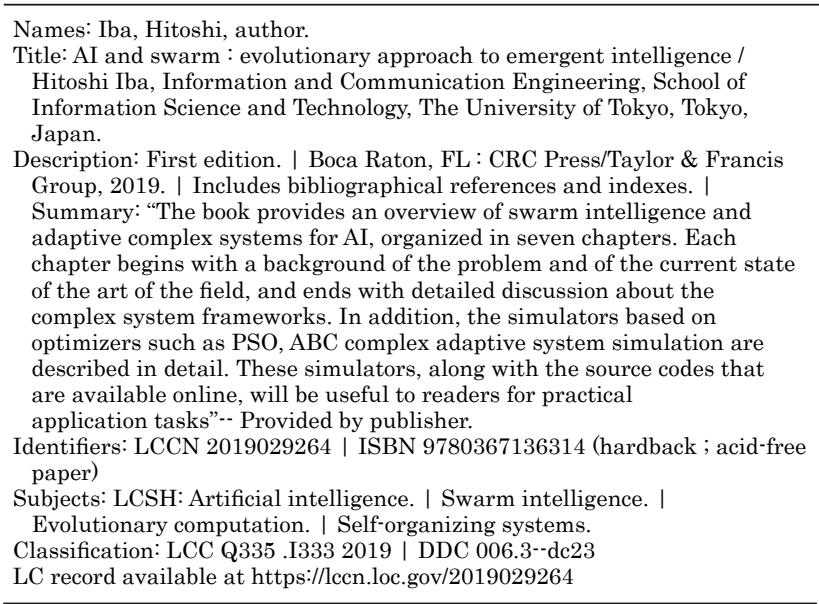

\section{Visit the Taylor \& Francis Web site at \\ http://www.taylorandfrancis.com}

and the CRC Press Web site at

http://www.crcpress.com 


\section{Preface}

We used to joke that AI means "Almost Implemented."

—Rodney Brooks

This book is an explanatory text about Artificial Intelligence (AI) and swarm, that is, "emergence" for AI. These days, we can say that we are in the middle of the third AI boom. One of the factors responsible for this is deep learning, which resulted in the evolution of neural networks as well as machine learning based on statistical theory. However, there remains the question of whether it is possible to create a true AI (a human-like general-purpose intelligence, the so-called "strong" AI). Many research results indicate that there is clearly more depth in human intelligence and cognition than is possible to express by AI techniques (“weak" AI).

For about 30 years, the author has studied evolution and emergent computation. The swarm mechanism gives us a glimpse of the principles of intelligence in humans and living beings. In this book, such topics related to artificial intelligence are explained in detail, from the theoretical background to the most recent progress, as well as future topics.

Some readers may wonder if some of the topics related to swarm do really belong to the realm of AI technology. Indeed, the essence of AI is to find problems. According to this line of thought, a problem is no longer considered to be AI as soon as it is solved. Brooks' joke in the beginning of this text symbolizes this point. Brooks is a researcher specializing in AI at MIT (Massachusetts Institute of Technology) since the 1980's. He is the author of numerous innovative ideas in the field of AI. He is also famous for having created the robot vacuum cleaner Roomba (he is the founder of iRobot in the US). From this perspective, is it possible to say that, because the vacuum cleaner robot is already in the market, it is no longer AI?

Current, AI seems to be surrounded by an excessively flamboyant advertisement of its technical applications. Of course, it is worth noting that 
the intention here is not to deny all this. The author himself is involved in such projects. However, being satisfied with the above is a different issue. Given that it is possible to link any type of intelligence to AI, we should not ignore basic research that focuses on the essence of cognition and life.

The objective of the author's research is to build a model of human cognitive functions from the perspective of "emergence" in order to achieve strong AI. In other words, the objective is to understand how intelligence appeared and interacted with the real world, as well as the causal relationships in terms of actual physical and chemical mechanisms. In that sense, this book intends not only to explain intelligent behavior itself, but also understand its causes and effects. In order to do that, I have explained the emergence of several types of human cognitive errors, cognitive dissonances, irrational behaviors, and cooperative/ betrayal actions.

Unfortunately, it is difficult to explain such phenomena using machine learning based on statistical models and deep learning based on big data, which constitute the core of current AI. On the contrary, a few hypotheses that contradict such approaches may be needed. In this book, research results related to brain mechanism are described, which is a factor that directly triggers intelligent behavior (called "proximate cause" or "physiological cause" in biological jargon), and the reasons for the evolution of living beings' behavior ("ultimate cause," or "biological/evolutional cause"). A few emergence simulation models are also introduced for better understanding. These approaches are important research efforts to clarify the essence of intelligence, in order to achieve true AI.

Most photographs depicting nature (modes of life and shapes of fish, patterns found in animals, images of Galapagos, Papua New Guinea, etc.) were shot by the author himself. Unfortunately, it is difficult for us to witness the evolution of nature on our own. However, it is possible to feel the driving force of emergence and the significance of diversity. In order to do that, it is suggested that you leave behind your PC or smartphone and see real things with your own eyes. The author has indulged in water life observation for about 30 years as a hobby, and still feels moved by it, reinforcing his conviction that nothing compares to seeing the real thing. Even though it is now possible to obtain almost any kind of image from the Internet, there are lots of things to be learned from real nature, and they are worth seeing.

Numerous things can be learned from actual living beings and from nature when studying swarms and AI. Therefore, in this book, the author has tried as much as possible to explain topics related to living beings and real life based on actual examples. It is the intent of the author that the readers will expand those topics and tackle new issues related to AI and swarm. 


\section{Acknowledgments}

This book is based on my class notes on "Artificial Intelligence" and "Simulation Theory". The assignments given to the students in class were often unusual and considered difficult or unanswerable. However, the reports that were submitted in return often contained impressive descriptions and deep insights which I always appreciated. In this book, some examples of answers and opinions contained in the submitted reports are used after necessary corrections and refinement. Although it is impossible to acknowledge everyone by their names, I would like to express his deepest gratitude to the students who made the efforts to write interesting reports.

Undoubtedly, those philosophical and interesting discussions with colleagues from the laboratory and institute where I belonged as a student, constitute the core of this book. I takes this opportunity to express my deepest gratitude to teachers, and senior and junior colleagues.

I also wish to express my gratitude to SmartRams Co., Ltd. for cover image design.

And last, but not least, I would like to thank his wife Yumiko and sons and daughter Kohki, Hirono and Hiroto, for their patience and assistance.

H. Iba

April 2019

Amami isl. (Galapagos of the East), Japan 
$\because$ Taylor \& Francis

Taylor \& Francis Group

http://taylorandfrancis.com 


\section{Contents}

Preface iii

Acknowledgments v v

Abbreviations $\quad$ xi

1. Introduction 1

1.1 What is AI? - Strong AI vs Weak AI 1

1.2 What is Emergence? 6

1.3 Cellular Automaton and Edge of Chaos 7

2. AI, Alife and Emergent Computation 15

$\begin{array}{ll}2.1 \text { Evolutionary Computation } & 15\end{array}$

2.1.1 What is Evolutionary Computation? 15

2.1.2 Evolution Strategy 22

2.1.3 Multi-objective Optimization $\quad 24$

2.2 How to Make a Bit? - Exploration vs Exploitation 29

2.3 Wireworld: A Computer Implemented as a Cellular 38

Automaton

2.4 Langton's Ant 43

3. Meta-heuristics 49

3.1 Ant Colony Optimization (ACO) 49

3.1.1 Collective Behaviors of Ants 49

3.1.2 Simulating the Pheromone Trails of Ants 51

3.1.3 Generating a Death Spiral $\quad 52$

3.1.4 ACO using a Pheromone Trail Model 53

3.2 Particle Swarm Optimization (PSO) 56

3.2.1 Collective Behavior of Boids $\quad 56$

$\begin{array}{lll}3.2 .2 & \text { PSO Algorithm } & 60\end{array}$ 
3.2.3 Comparison with GA

3.2.4 Collective Memory and Spatial Sorting 66

3.2.5 Boids Attacked by an Enemies 71

3.3 Artificial Bee Colony Optimization (ABC) 76

3.4 Firefly Algorithms $\quad 84$

3.5 Cuckoo Search 86

3.6 Harmony Search (HS) 89

3.7 Cat Swarm Optimization (CSO) 91

3.8 Meta-heuristics Revisited 94

4. Emergent Properties and Swarm Intelligence 97

4.1 Reaction-Diffusion Computing 97

4.1.1 Voronoi Diagram Generation 98

4.1.2 Thinning and Skeletonization for Image 109 Understanding

4.2 Queuing Theory and Traffic Jams 112

4.2.1 Most Random Customers and Poisson Arrival 112

4.2.2 Poisson Distribution and Cognitive Errors 115

4.2.3 Queue Management and Scheduling 119

4.3 Silicon Traffic and Rule $184 \quad 125$

4.4 Segregation and Immigration: What is Right? 131

5. Complex Adaptive Systems 137

5.1 Diffusion-Limited Aggregation (DLA) 137

5.2 How do Snowflakes Form? 138

5.3 Why do Fish Patterns Change? 149

5.3.1 Turing Model and Morphogenesis $\quad 149$

5.4 BZ Reaction and its Oscillation 153

5.5 Why do We have Mottled Snakes? Theory of Murray 155

6. Emergence of Intelligence 161

6.1 Evolution of Cooperation and Defection 161

6.1.1 How to Clean a Fish 161

6.1.2 The Prisoner's Dilemma 163

6.1.3 Iterated Prisoner's Dilemma 166

6.1.4 ESS: Evolutionarily Stable Strategy 173

$\begin{array}{lll}6.1 .5 & \text { IPD using GA } & 175\end{array}$

6.1.6 IPD as Spatial Games 179

6.1.7 Can the Dilemma be Eliminated with 183 Quantum Games?

6.1.8 The Ultimatum Game: Are Humans Selfish or 185 Cooperative?

6.2 Evolutionary Psychology and Mind Theory 
6.3 How does Slime Solve a Maze Problem? Slime Intelligence

6.4 Swarm Robots

6.4.1 Evolutionary Robotics and Swarm

6.4.2 Transportation Task for Swarm

6.4.3 Occlusion-based Pushing (OBP)

6.4.4 Guide-based Approach to OBP

203

6.4.5 Let us See How they Cooperate with each other

7. Conclusion

7.1 Summary and Concluding Remarks

Index 
$\because$ Taylor \& Francis

Taylor \& Francis Group

http://taylorandfrancis.com 


\title{
Abbreviations
}

\author{
ABC : artificial bee colony \\ ACO : ant colony optimization \\ AI : artificial intelligence \\ AL : artificial life \\ ANN : artificial neural network \\ ASEP : asymmetric simple exclusion process \\ BCA : Burgers cellular automaton automata \\ CA : cellular automata \\ CS : cuckoo search \\ CSO : cat swarm optimization \\ DLA : diffusion-limited aggregation \\ EA : evolutionary algorithms \\ EANN : evolutionary ANN \\ EC : evolutionary computation \\ EDA : estimation of distribution algorithm \\ EDD : earliest due date \\ EP : evolutionary programming \\ ES : evolution strategy \\ ESS : evolutionarily stable strategy \\ FA : firefly algorithm \\ FIFO : first-in, first-out \\ GA : genetic algorithms \\ GP : genetic programming \\ HS : harmony search \\ IPD : iterated prisoner's dilemma \\ JSSP : job scheduling problem \\ OBP : occlusion-based pushing \\ PSO : particle swarm optimization
}


SA : simulated annealing

SPT : shortest processing time

TFT : tit for tat

TSP : traveling salesman problem

UCB : upper confidence bound

WSLS : Win-Stay-Lose-Shift

ZD : zero-determinant strategy 


\section{Chapter 1}

\section{Introduction}

A sonnet written by a machine would be better appreciated by another machine.

-Alan Turing

\subsection{What is AI? - Strong AI vs Weak AI}

AI (artificial intelligence) refers to the implementation of intelligence on a computer and is divided into two hypotheses.

Strong AI The viewpoint that true intelligence can be implemented on a computer, also known as general AI.

Weak AI The viewpoint that computers can merely give the impression of intelligence, also known as narrow AI.

In the same manner, artificial life (AL), which is mentioned later, can be defined in terms of strong AL and weak AL.

"Weak AI" is an application of AI technologies to enable a high-functioning system that replicates human intelligence for a specific purpose. In fact, there are breakthroughs in weak AI.

In this book we consider simulation in the sense of "strong AI". More precisely, the rationale behind this approach is that "the appropriately programed computer really is a mind, in the sense that computers, given the right programs, can be literally said to understand and have other cognitive states." 


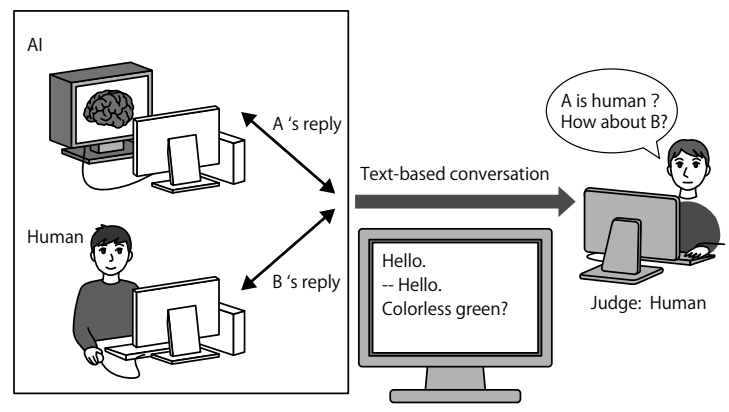

Figure 1.1: Turing test.

Realizing such a computer is nontrivial, since the definition of "intelligence" is difficult in the first place. Therefore, if a claim is made that AI (in the strong sense) has been created, what would be the most appropriate way to evaluate it?

To this end, Alan Turing ${ }^{1}$ proposed a test of a machine's capacity to exhibit intelligent behavior, now called the "Turing test", which, despite being powerful, is the subject of numerous disputes (Fig. 1.1). The question of whether machines can think was considered in great depth by Turing, and his final opinion was affirmative. The Turing test can be translated into modern terms in the form of a game involving the exchanging of messages via a discussion board:

- One day, two new users, A and B, join the discussion board.

- When a message is sent to $\mathrm{A}$ and $\mathrm{B}$, they both return apt responses.

- Of $\mathrm{A}$ and $\mathrm{B}$, one is human and the other is a computer.

- However, it is impossible to determine which is which, regardless of the questions asked.

If a program passes this test (in other words, the computer cannot be identified), the program can be said to simulate intelligence (as long as the questions are valid). A similar contest, named the "The Loebner prize" after its patron, the American philanthropist Hugh Loebner, is held online ${ }^{2}$. Although an award of 100,000 US dollars and a solid gold medal has been offered since 1990, so far, not a single machine participating in the contest has satisfied the criteria for winning.

Nevertheless, a number of problems with the Turing test have been pointed out, and various critical remarks have been issued about potential implementation

\footnotetext{
${ }^{1}$ Alan Turing (1912-1954): British mathematician. He worked on deciphering the Enigma encryption used by the German Army during World War II. He is considered the "father of computer science." The Turing machine for computing theory and the Turing model for morphogenesis are some of his pioneering achievements. Apple's bitten apple logo is allegedly an homage to Turing.

${ }^{2}$ http://www.loebner.net/Prizef/loebner-prize.html
} 


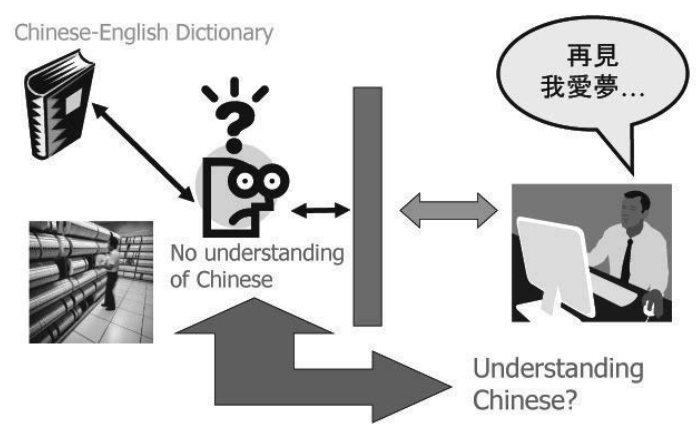

Figure 1.2: A Chinese room.

of AI. A notable example is the challenge to the very "definition of intelligence" by John Searle ${ }^{3}$, who questioned the foundations of the Turing test by creating a counter thought experiment. Searle's experiment, known as the "Chinese room," can be summarized as follows.

A person is confined to a room with a large amount of written material on the Chinese language (Fig. 1.2). Looking inside the room is impossible, and there are only input and output boxes for submitting sentences and obtaining responses. Having no understanding of Chinese, the person cannot distinguish between different Chinese characters (for this purpose, we assume that the person is British and not Japanese). Furthermore, the person is equipped with a comprehensive manual (written in English) containing rules for connecting sets of Chinese characters. Let us consider that a person who understands Chinese is leading a conversation by inserting questions written in Chinese into the input box and retrieving answers from the output box. Searle provides the following argument.

Suppose that the person quickly becomes truly proficient at manipulating Chinese characters in accordance to the instructions, and that the person outside the room also becomes proficient at providing instructions. Then, the answers prepared by the person inside the room would become indistinguishable from answers provided by a Chinese person. Nobody would consider, simply by looking at the provided answers, that the person inside the room does not understand Chinese. However, in contrast to English, in the case of Chinese, the person in the room prepares the answers by formally manipulating characters, without any understanding whatsoever.

It cannot be said that true understanding is achieved simply by looking at the typeface while performing manipulations in accordance with a formal set of rules. However, as demonstrated by the "Chinese room" thought experiment,

\footnotetext{
${ }^{3}$ John Rogers Searle (1932-): American philosopher. He is known for his criticism of artificial intelligence. In 1980, he proposed the "strong and weak AI" classification.
} 
under specific conditions, human-like behavior can be fabricated by both humans and machines if appropriate formal rules are provided. Searle, therefore, argues that strong $\mathrm{AI}$ is impossible to realize.

Various counterarguments have been considered in response to Searle, and questions that would probably occur to most people include

- Can conversion rules be written for all possible inputs?

- Can such an immense database actually be searched?

However, these counterarguments are devoid of meaning. The former rejects the realization of $\mathrm{AI}$ in the first place, and the latter cannot be refuted in light of the possibility that ultra-high-speed parallel computing or quantum computing may exist in the future. Thus, neither one can serve as the basis of an argument.

One powerful counterargument is based on system theory. Although the person in the room certainly lacks understanding, he constitutes no more than a single part of a larger system incorporating other elements, such as the paper and the database, and this system as a whole does possess understanding. It is the equivalent to the fact that, even for Chinese, cranial nerve cells do not understand the language by themselves. This point is integral to the complex systems regarded in this book. The level at which intelligence is sought depends on the observed phenomenon, and if the phenomenon is considered as being an emergent property, the validity of the above system theory can be recognized. Moreover, a debate is ongoing about whether intelligence should be thought of as an integrated concept or as a phenomenon that is co-evolving as a result of evolution.

On the other hand, Searle reargues that "if the manual is fully memorized and the answers are given without external help, it is still possible not to understand the Chinese language". Recently, Levesque et al. [67] counterpoint against Searle's criticism has been made based on a theory of computation. This is described in the "addition room argument" as follows:

- Consider the addition room, where twenty ten-digit numbers are to be added.

- Suppose there is a person in the room who does not know how to add and a manual on addition is placed in the middle of the room.

- At this time, if the human perfectly grasps the content of the manual and does all the operations in their head, then is it still possible to create a manual without understanding addition?

For the "addition room," the following manual immediately comes to mind:

- Memorize one-digit additions.

- Reduce two or more-digit numbers to one-digit and add. 
However, this is exactly the way we learned in elementary school. Therefore, knowing this manual means being acquainted with the addition algorithm, thus, it is possible to say that addition is understood.

Let us think about a little bit more primitive manual described below:

- Go to the same chapter as the first number.

- Go to the section with the same number as the second number within that chapter.

- Furthermore, go to the subsection with the same number as the third number within that section.

- Repeat that for all twenty numbers.

- When everything is over, there is a number with up to twelve-digits, so return that number and exit.

This manual merely lists the calculation results in the same way as a dictionary. Just like in the Chinese room argument, a human following this manual does not add and additionally does not understand the calculation at all. So, was Searle's claim correct?

Let us consider here the computational complexity of this manual. The chapter corresponding to the first number requires ten to the tenth power. Each chapter consists of ten to tenth power of sections. Since this is repeated twenty times, it becomes 10 to 10 power to 20 power $=10^{200}$ of items. It is said that the number of molecules in the universe is around $10^{100}$. Therefore, such a large manual can never be made. From this, it can be understood that Searle's claim is mistaken, from a computational theory. This is true as far as this manual is concerned, but Searle himself did not specify the composition method of the manual, so there may be recurring objections.

Recently, machine translation is accomplished using a huge database and statistical processing. The famous one is Google's machine translation. Past machine translation was a classical AI based on natural language understanding. Unfortunately, it was not always effective. On the other hand, Google's machine translation does not understand natural language at all. This software statistically joins translated words using a huge database (human translations, e.g., minutes of the United Nations). As a result, it won the 2006 machine learning contest with an overwhelming difference. This kind of translation method is possible due to the power of modern computers and internet connection. This approach may be a solution to the Chinese room argument. 


\subsection{What is Emergence?}

Originally, emergence (emergent property) was a term in biology. A good example of that property is seen in ant social life. Each ant has a simple mechanical behavior. However, the ant colony as a whole acts in a highly intelligent collective manner (collective behavior), according to the distribution pattern of food and enemies, therefore increasing the survival rate of the colony. As a result, a caste system emerges, consisting of individuals specialized in doing different jobs, where a social division of labor and cooperation will be seen (see Fig. 1.3). There are no rules (programs) that govern the behavior of the whole colony. Nonetheless, an emergence of intellectual global behavior, brought about by collective action of simple programs (individual ants), is observed.
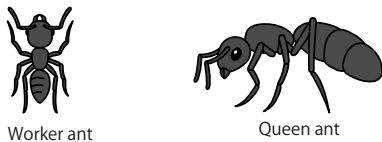

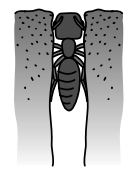

Soldier ant (Colobopsis) whose heads work like a hole cap, close the entrance of the ant nest like a living door.

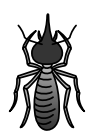

Infertility caste

(Nasutitermes. Takasagoensis), whose heads look like water guns, blow toxic substances on approaching enemies.

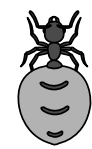

Satiated working ant (Myrmecocystus) lives all their lives inside the nest as a living deposit.

Figure 1.3: Job seperation emerged [123].

In emergence, arising of the macroscopic phenomena from micro interactions has become a central idea. This phenomenon is observed in various fields, such as morphological formation (pattern generation, see sec. 5.3) or group formation (see sec. 3.2) by animal populations in ecology. Emergent phenomenon can be seen even in economy and finance. For example, in a financial market, each individual (participants, investors) pursues their own profit based on local information, thus, interacts with other individuals (speculative behavior). As a result, when we look at the entire financial market, phenomena such as "price movement of sidelines" and "nervous movement" are observed. On the other hand, each market participant does not necessarily behave in a nervous manner or wait watchfully. In this manner, generation of a macro phenomenon that is not described by micro interactions is emergence. E.O. Wilson" ${ }^{4}$ claims that "the higher nature of life is emergent [109]". In other words, the higher-level phenomenon, leading to the creation of biological individual from cells and society from in-

\footnotetext{
${ }^{4}$ Edward Osborn Wilson (1929-): American entomologist. Researcher of sociobiology and biodiversity. See also the footnote of 188 page.
} 
dividuals, cannot be described only by knowledge of the nature of components constituting lower levels.

There are two types of emergence [32]:

Weak emergence New property appears as a result of the interactions of elemental levels. Emergent property can be reduced to individual components.

Strong emergence The newly emerged property cannot be reduced because it is more than the sum of its components. Laws governing the property cannot be predicted by understanding the laws governing the structure of another level.

By becoming a group, it spontaneously acquires properties and trends not included in the underlying rule. Emergence is recognized in various fields, such as physics, biology, chemistry, sociology, and art. However, strong emergence cannot be dealt with in traditional physics and reductionist approaches.

The author thinks that human intelligence could be explained through emergence. However, many brain researchers and neuroscientists are critical towards emergence. Many of them take a reductionist method and dislike the idea of a ghost in the brain, which cannot be explained deterministically. On the other hand, it is known that the combination of the network configuration to derive the same behavior is extremely large. Therefore, it is a significant obstacle for the neuroscientist, because further analysis of the neural circuit leads only to an understanding of the mechanism, and not how it actually operates. Recognizing that there are different levels in the organization is crucial to the understanding of the phenomenon of emergence [32]. Recently, the mechanism by which directives traverse from micro to macro level in a causal manner is being mathematically researched by the neuroscientists [50].

\subsection{Cellular Automaton and Edge of Chaos}

The eminent mathematician John von Neumann ${ }^{5}$ studied self-reproducing automata in 1946, shortly before his death. He found that self-reproduction is possible with 29 cell states, and proved that a machine could not only reproduce

\footnotetext{
${ }^{5}$ Jon von Neumann (1903-1957): Hungarian-born American mathematician. As symbolized by the gossip that circulated around Princeton that he slept with a mystery novel as his pillow in the day and learned mathematics from the devil at night, he conducted pioneering research in various areas, such as mathematics, physics, engineering, computer science, economics, meteorology, psychology, and political science, having substantial influence in posterior advances in these areas. He was also deeply involved with American nuclear policy and was part of the Manhattan project.
} 
Table 1.1: State of cell in next step.

\begin{tabular}{|c|c|c|}
\hline Current state of cell & States of neighbor cells & State in next step \\
\hline On & two or three are "on" & On \\
& Other cases & Off \\
\hline Off & three are "on" & Off \\
& Other cases & Off \\
\hline
\end{tabular}

itself, but could also build machines more complex than itself. The research stopped because of his death; however, in 1966, Arthur Burks edited and published von Neumann's manuscripts. John Conway, a British mathematician, expanded on the work of von Neumann and, in 1970, introduced the Game of Life, which attracted immense interest. Some people became "Game of Life hackers," programmers and designers more interested in operating computers than in eating; they were not the criminal hackers of today. Hackers at MIT rigorously researched the Game of Life, and their results contributed to advances in computer science and artificial intelligence. The concept of the Game of Life evolved into the "cellular automata" (CA), which is still widely studied in the field of artificial life. Most of the research on artificial life shares much in common with the world where hackers played in the early days of computers.

The Game of Life is played on a grid of equal-sized squares (cells). Each cell can be either "on" or "off". There are eight adjacent cells to each cell in a twodimensional grid (above and below, left and right, four diagonals). This is called the Moore neighborhood. The state in the next step is determined by the rules outlined in Table 1.1. The "on" state corresponds to a "•" in the cell, whereas the "off" state corresponds to a blank. The following interesting patterns can be observed with these rules.

1. Disappearing pattern (diagonal triplet)

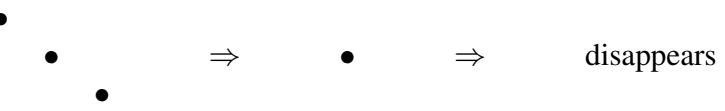

2. Stable pattern $(2 \times 2$ block $)$

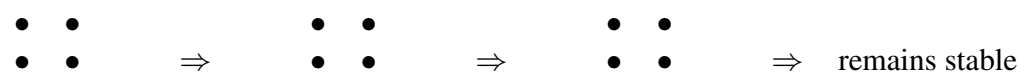

3. Two-state switch (Flicker, where vertical triplets and horizontal triplets appear in turn)

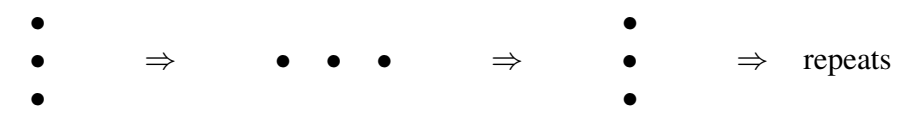


4. Glider (pattern moving in one direction)

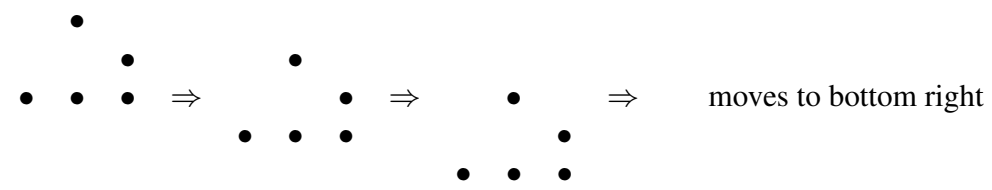

"Eaters" that stop gliders and "glider guns" that shoot gliders can be defined, and glider guns are generated by the collision of gliders. Such self-organizing capabilities mean that the Game of Life can be used to configure a universal Turing machine. The fundamental logic gates (AND, OR, NOT) consist of glider rows and disappearing reactions, and blocks of stable patterns are used as memory. However, the number of cells needed in a self-organizing system is estimated to be about 10 trillion ( 3 million $\times 3$ million). The size would be a square whose sides are $3 \mathrm{~km}$ long, if $1 \mathrm{~mm}^{2}$ cells are used.

Consider a one-dimensional Game of Life, one of the simplest cellular automata. The sequence of cells in one dimension at time $t$ is expressed as follows:

$$
a_{t}^{1}, a_{t}^{2}, a_{t}^{3}, \cdots
$$

Here, each variable is either 0 (off) or 1 (on). The general rule used to determine the state $a_{t+1}^{i}$ of cell $i$ at time $t+1$ can be written as a function $F$ of the state at time $t$ as

$$
a_{t+1}^{i}=F\left(a_{t}^{i-r}, a_{t}^{i-r+1}, \cdots, a_{t}^{i}, \cdots, a_{t}^{i+r-1}, a_{t}^{i+r}\right)
$$

Here, $r$ is the radius, or range of cells that affects this cell.

For instance, a rule for $r=1$,

$$
a_{t+1}^{i}=a_{t}^{i-1}+a_{t}^{i}+a_{t}^{i+1}(\bmod 2)
$$

results in the determination of the next state as follows:

time $t \quad: \quad 0010011010101100$

time $\mathrm{t}+1:$ : $* 11111001010001 *$

An interesting problem is the task of finding the majority rule. The task is to find a rule that would ultimately end in a sequence of all $1(0)$ if the majority of the cells are $1(0)$ with the minimum radius $(r)$ possible for a one-dimensional binary sequence of a given length. The general solution to this problem is not known.

A famous example is a majority rule problem with length 149 and radius 3. The problem is reduced to finding a function that assigns 1 or 0 to an input with 7 bits $\left(=3+1+3\right.$, radius of 3 plus itself); therefore, the function space is $2^{2^{7}}$.

How can a cellular automaton (CA) obtain a solution to the majority problem? 
One method is to change the color (black or white) of a cell to the majority of its neighboring cells. However, this method does not work well, as shown in Fig. 1.4, because it results in a fixed pattern divided into black and white.

In 1978, Gacs, Kurdyumov and Levin found the rules (GLK) regarding this problem. Lawrence Davis obtained an improved version of these rules in 1995, and Rajarshi Das proposed another modification. There is also research to find effective rules through GAs (genetic algorithms) or GP (genetic programming). The concept of Boolean functions is applied when GP is used. The fitness value is defined by the percentage of correctly processed sequences out of 1000 randomly generated sequences of length 149 .

Rules determined by various methods are summarized in Table 1.2. Here, the transition rules are shown from 0000000 to 1111111 in 128-bit form. In other words, if the first bit is 0 ,

$$
F(0000000)=0
$$

Table 1.3 is a comparison of different rules. The rules obtained using GP were very effective; reference [4] contains the details of this work.

Figure 1.5 shows how a CA obtained by GA can solve this problem well [75, 76]. The regions that were initially dominated by black or white cells become regions that are completely occupied by either black or white cells. A vertical line always exists at locations where a black region to the right meets a white region to the right. In contrast, a triangular region with a chessboard pattern forms where a white region to the right meets a black region to the right.
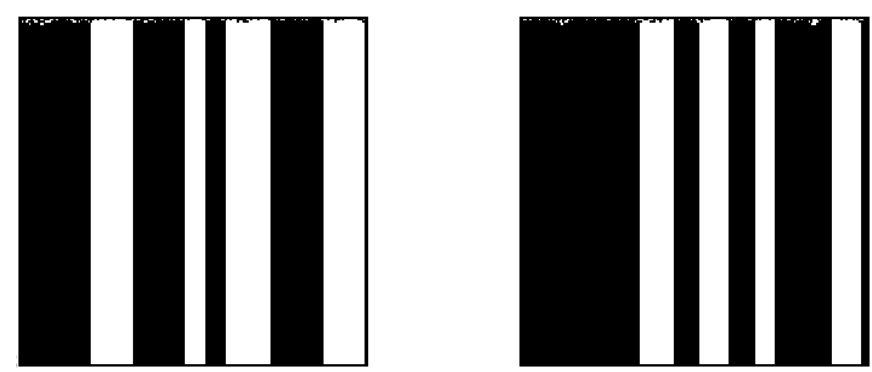

Figure 1.4: CA carrying out majority voting (Oxford University Press, Inc., [76]).

The two edges of the growing triangular region at the center with a chessboard pattern grow at the same pace, progressing the same distance per unit time. The left edge extends until it collides with a vertical boundary. The right edge barely avoids the vertical boundary at the left (note that the right and left edges are connected). Therefore, the left edge can extend for a shorter length, which means that the length of the white region limited by the left edge is shorter than 
Table 1.2: Majority rules.

\begin{tabular}{|c|l|}
\hline Name of rule (year) & Transition rules \\
\hline GKL(1978) & 000000000101111100000000010111110000000001011111 \\
& 00000000010111110000000001011111111111110101111 \\
& 00000000010111111111111101011111 \\
\hline Davis(1995) & 000000000010111100000011010111110000000000011111 \\
& 11001111000111110000000000101111111111000101111 \\
& 0000000000011111111111100011111 \\
\hline Das(1995) & 000001110000000000000111111111110000111100000000 \\
& 0000111111111110000111100000000000001111111111 \\
\hline GP(1995) & 00001111001100010000111111111111 \\
& 000001010000000001010101000001010000010100000000 \\
& 01010101000001010101010111111111010101011111111 \\
\hline
\end{tabular}

Table 1.3: Performance in the majority problem.

\begin{tabular}{|c|c|c|}
\hline Rule & Performance & Number of tests \\
\hline GKL & $81.6 \%$ & $10^{6}$ \\
\hline Davis & $81.8 \%$ & $10^{6}$ \\
\hline Das & $82.178 \%$ & $10^{7}$ \\
\hline GA & $76.9 \%$ & $10^{6}$ \\
\hline GP & $82.326 \%$ & $10^{7}$ \\
\hline
\end{tabular}

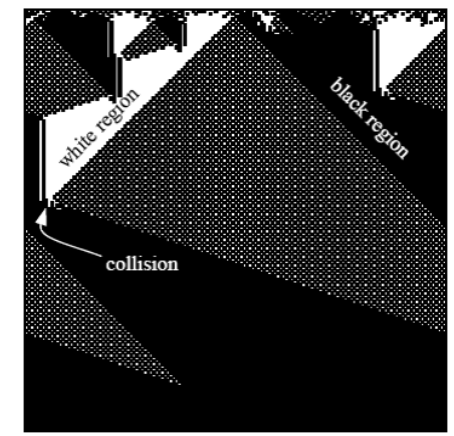

Figure 1.5: Behavior of CA driven by GA (Oxford University Press, Inc., [76]).

the length of the black region limited by the right edge. The left edge disappears at the collision point, allowing the black region to grow. Furthermore, the two edges disappear at the bottom vertex and the entire lattice row becomes black, showing that the correct answer was obtained. 


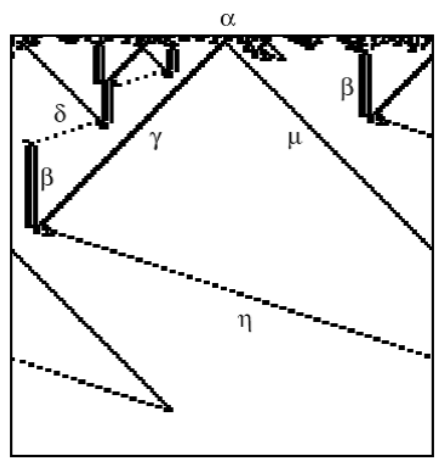

Figure 1.6: Explanation of CA behavior from collision of particles (Oxford University Press, Inc., [76]).

Melanie Mitchell analyzed the information processing structure on CA that evolved through GA by using the behavior of dynamic systems [75, 76]. The boundaries between simple regions (edges and vertical boundaries) are considered carriers of information, and information is processed when these boundaries collide. Figure 1.6 shows only the boundaries in Fig. 1.5. These boundary lines are called "particles" (similar to elementary particles in a cloud chamber used in physics). The particles are represented by Greek letters following the tradition in physics. Six particles are generated in this CA. Each particle represents a different type of boundary. For instance, $\eta$ is the boundary between a black region and a chessboard-patterned region. A number of collisions of particles can be observed. For example, $\beta+\gamma$ results in the generation of a new particle $\eta$, and both particles annihilate in $\mu+\eta$.

It is easy to understand how information is coded and calculated when the behavior of CA is expressed in the language of particles. For instance, $\alpha$ and $\beta$ particles are coded with different information on the initial configuration. $\gamma$ particles contain information that this is the boundary with a white region, and a $\mu$ particle is a boundary with a white region. When a $\gamma$ particle collides with a $\beta$ particle before colliding with a $\mu$ particle, this means that the information carried by $\beta$ and $\gamma$ particles becomes integrated, showing that the initial large white region is smaller than the initial large black region that shares a boundary. This is coded into the newly generated $\eta$ particle.

Stephen Wolfram ${ }^{6}$ systematically studied the patterns that form when different rules (eq. (1.2)) are used. He grouped the patterns generated by onedimensional CA into four classes.

\footnotetext{
${ }^{6}$ Stephen Wolfram (1959-): British theoretical physicist. At the age of 20, he obtained his Ph.D. degree from California Institute of Technology for his research on theoretical physics. In 1987, he found the company Wolfram Research. He released the mathematical software Mathematica, which is used for research in natural sciences and numerous other fields.
} 
Class I All cells become the same state and the initial patterns disappear. For example, all cells become black or all cells become white.

Class II The patterns converge into a striped pattern that does not change or a pattern that periodically repeats.

Class III Aperiodic, chaotic patterns appear.

Class IV Complex behavior is observed, such as disappearing patterns or aperiodic and periodic patterns.

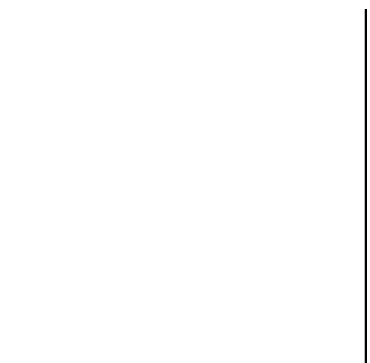

(a) Class I

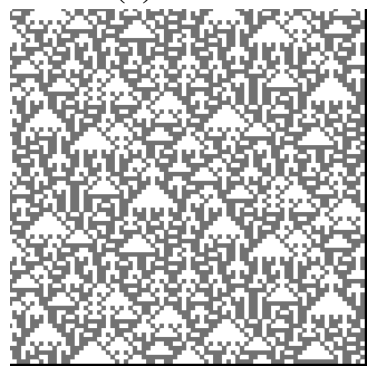

(c) Class III

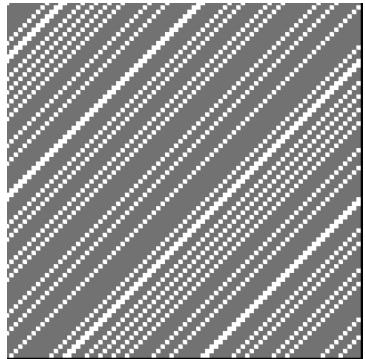

(b) Class II

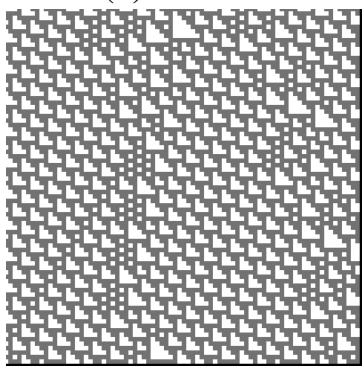

(d) Class IV

Figure 1.7: Examples of patterns.

Examples of these patterns are shown in Fig. 1.7. The following are the rules behind these patterns (radius 1):

- Class I: Rule 0

- Class II: Rule 245

- Class III: Rule 90

- Class IV: Rule 110 
Here, transition rules are expressed in $2^{2^{3}}$ bits from 000 to 111 , and the number of the rule is the decimal equivalent of those bits. For instance, the transition rules for Rule 110 in Class IV are as follows [71]:

$$
01101110_{\text {binary }}=2+2^{2}+2^{3}+2^{5}+2^{6}=110_{\text {decimal }}
$$

In other words, 000,100 and 111 become 0 , and 001, 010, 011, 101, 110 become 1 .

Rule 110 has the following interesting characteristics in computer science.

1. It is computationally-universal [126].

2. It shows $1 / f$ fluctuation [83].

3. Its prediction is P-complete [82].

Kauffman and Packard proposed the concept of the "edge of chaos" from the behavior of CA as discussed above. This concept represents Class IV patterns where periodic patterns and aperiodic, chaotic patterns are repeated. The working hypothesis in artificial life is "life on the edge of chaos." 


\section{References}

[1] Adamatzky, A., "Voronoi-like partition of lattice in cellular automata," Mathematical and Computer Modelling, vol.23, no.4, pp.51-66, 1996.

[2] Adamatzky, A., Costello, B., and Asai, T., Reaction-Diffusion Computers, Elsevier Science, 2005.

[3] Alkilabi, M.H.M., Lu, C., and Tuci, E., "Cooperative Object Transport Using Evolutionary Swarm Robotics Methods," in Proc. of the European Conference on Artificial Life (ECAL), pp.464-471, 2015.

[4] Andre, D., Bennett III, F.H., and Koza, J.: "Evolution of Intricate LongDistance Communication Signals in Cellular Automata using Genetic Programming," in Artificial Life V: Proceedings of the Fifth International Workshop on the Synthesis and Simulation of Living Systems, 1996.

[5] Arthur, W.B., Increasing Returns and Path Dependence in the Economy, University of Michigan Press, 1994.

[6] Auer, P., Cesa-Bianchi, N., and Fischer, P., "Finite-time analysis of the multiarmed bandit problem," Machine Learning, vol.47, no.2, pp.235-256, 2002.

[7] Axelrod, R.: “The Evolution of Cooperation,” Basic Books, New York, NY, 1984.

[8] Axelrod, R.: “An evolutionary approach to norms," American Political Science Review, vol.80, no.4, pp.1095-1111, 1986.

[9] Bäck, T., Hoffmeister, F., and Schwefel, H.-P., "An Survey of Evolution Strategies," in Proc. 4th International Conference on Genetic Algorithms (ICGA91), pp.2-9, Morgan Kaufmann, 1991.

[10] Bäck, T., "An overview of evolutionary algorithms for parameter optimization," Evolutionary Computation, vol.1, no.1, pp.1-23, 1993. 
[11] Bellman, R., Adaptive Control Processes-A Guided Tour, Princeton University Press, 1961.

[12] Bonabeau, E., Dorigo, M., and Theraulaz, G., Artificial Intelligence from Natural to Artificial Systems, Oxford University Press, New York, 1999.

[13] Brockman, J., This Explains Everything: 150 Deep, Beautiful, and Elegant Theories of How the World Works, Harper Perennial, 2013.

[14] Civicioglu, P., and Besdok, E., "A conceptual comparison of the Cuckoosearch, particle swarm optimization, differential evolution and artificial bee colony algorithms," Artificial Intelligence Review, vol.39, no.4, pp.315-346, 2013.

[15] Chen, J., Gauci, M., Li, W., Kolling, A., and Gro $\beta$, R., "Occlusion-based cooperative transport with a Swarm of miniature mobile robots," IEEE Transactions on Robotics, vol.31, no.2, pp.307-321, 2015.

[16] Chu, S.-C., Tsai, P.-W., and Pan, J.-S., "Cat Swarm Optimization," in Proc. Pacific Rim International Conference on Artificial Intelligence (PRICAI 2006), pp.854-858, 2006.

[17] Clarke, R.D., "An application of the Poisson distribution," vol.72, no.3, Journal of the Institute of Actuaries, 1946.

[18] Clerc, M., and Kennedy, J.: "The Particle Swarm: Explosion, Stability, and Convergence in a Multimentional Complex Space," IEEE tr. Evolutionary Computation, vol.6, no.1, pp.58-73, 2002.

[19] Cliff, D, Harvey, I., and Husbands, P., "Explorations in evolutionary robotics," Adaptive Behavior, vol.2, pp.72-110, 2000.

[20] Cohen, M.D., Riolo, R.L., and Axelrod, R.: "The emergence of social organization in the prisoner's dilemma: How context-preservation and other factors promote cooperation," Santa Fe Institute working paper 99-01-002, http://cscs . umich.edu/research/techReports.html, 1999.

[21] Couzin, I.D., Krausew, J., Jamesz, R., Ruxtony, G.D., and Franksz, N.R., "Collective memory and spatial sorting in animal groups," Journal of Theoretical Biology, vol.218, no.1, pp.1-11, 2002.

[22] David, P.A., "Clio and the economics of QWERTY," The American Economic Review, vol.75, no.2, Papers and Proceedings of the Ninety-Seventh Annual Meeting of the American Economic Association, pp.332-337,1985.

[23] Davies, N.B., Krebs, J.R., and West, S.A., "An Introduction to Behavioural Ecology," Wiley-Blackwell, 4th Edition, 2012. 
[24] Dawkins, R.: The selfish gene, Oxford Univ. Press, 1991.

[25] Dawkins, R.: The God Delusion, Mariner Books, 2008.

[26] Deb, K.D., Pratap, A., Agarwal, S., and Meyarivan, T., "A fast and elitist multiobjective genetic algorithm : NSGA-II," IEEE Transactions on Evolutionary Computation, vol.6, no.2, pp.182-197, 2002.

[27] Devlin, K., The Math Instinct: Why You're a Mathematical Genius (Along with Lobsters, Birds, Cats, and Dogs), Basic Books, 2009.

[28] Dewdney, A.K., “The hodgepodge machine makes waves," Scientific American, vol.259, no.2, 1988.

[29] Dewdney, A.K., "The cellular automata programs that create wireworld, rugworld and other diversions, Computer Recreations," Scientific American, 72, pp.146-149 Jan. 1990.

[30] Dorigo, M., and Gambardella, L.M.: "Ant colonies for the traveling salesman problem”, Tech. Rep. IRIDIA/97-12, Universite Libre de Bruxelles, Belgium, 1997.

[31] Fung, K., Numbers Rule Your World: The Hidden Influence of Probabilities and Statistics on Everything You Do, McGraw-Hill Education, 2010.

[32] Gazzaniga, M.S., Who's in Charge?: Free Will and the Science of the Brain, Ecco, 2011.

[33] Geem, Z.W., Kim, J.H., and Loganathan, G.V., "A new heuristic optimization algorithm: Harmony search," Simulation, vol.76, no.2, pp.60-68, 2001. Physical Review E, vol.79, 2009.

[34] Ghosh, A., Dehuri, S., and Ghosh, S. (eds.), "Objective Evolutionary Algorithms for Knowledge Discovery from Databases," Springer, 2008.

[35] Goldberg, E., The New Executive Brain: Frontal Lobes in a Complex World, Oxford University Press, 2009.

[36] Goldberg, D.E., Genetic Algorithms in Search, Optimization and Machine Learning, Addison Wesley, 1989.

[37] Goss, S., Aron, S., Deneubourg, J.L., and Pasteels, J.M.: "Self-organized shortcuts in the argentine ant," Naturwissenschaften, vol. 76, pp. 579-581, 1989.

[38] Gracia-Lázaro, C., Ferrer, A., Ruiz, G., Tarancón, A., Cuesta, J.A., Sánchez, A., and Morenoa, Y., "Heterogeneous networks do not promote cooperation when humans play a Prisoner's Dilemma," Proceedings of the National Academy of Sciences, PNAS, vol.109, no.32, pp.12922-1292, 2012. 
[39] Grant, P.R., and Grant, B.R., How and Why Species Multiply: The Radiation of Darwin's Finches, Princeton Series in Evolutionary Biology, Princeton Univ Press, 2011.

[40] Gravner, J., and Griffeath, D., "Modeling snow crystal growth II: A mesoscopic lattice map with plausible dynamics," Physica D: Nonlinear Phenomena, vol.237, no 3, pp.385-404, 2008.

[41] Gravner, J., and Griffeath, D., "Modeling snow-crystal growth: A three- dimensional mesoscopic approach," Physical Review E, vol.79, 2009.

[42] Gould, S.J., Bully for Brontosaurus: Reflections in Natural History, W.W.Norton \& Co.Inc., 1992.

[43] Haidt, J., The Righteous Mind: Why Good People Are Divided by Politics and Religion, Vintage, 2013.

[44] Harman, O., The Price of Altruism: George Price and the Search for the Origins of Kindness, W.W.Norton \& Co.Inc., 2011.

[45] He, C., Noman, N., and Iba, H., "An Improved Artificial Bee Colony Algorithm with Non-separable Operator," in Proc. of International Conference on Convergence and Hybrid Information Technology, 2012.

[46] Hepper, F., and Grenader, U., "A stochastic nonlinear model for coordinated bird flocks," AAAS publication, Washington,DC, 1990.

[47] Herdy, M., "Appication of the Evolution Strategy to Discrete Optimization Problems," in Parallel Problem Solving from Nature (PPSN), Schwefel, H.-P. and Männer, R. (eds.), pp.188-192, Springer-Verlag, 1990.

[48] Higashi, N., and Iba, H.: "Particle Swarm optimization with gaussian mutation," Proceedings of IEEE Swarm Intelligence Symposium (SISO3), pp.7279, 2003.

[49] Hilditch, C.J., Linear Skeletons From Square Cupboards in Meltzer,B. \& Michie,D. (eds.), Machine Intelligence 4, pp.403-420, Edinburgh University Press, 1969.

[50] Hoel, E.P., Albantakis, L., and Tononi, G., "Quantifying causal emergence shows that macro can beat micro," Proceedings of the National Academy of Sciences, PNAS, vol.110, no.49, pp.19790-19795, 2013.

[51] Holland, J.H.: Adaptation in Natural and Artificial Systems. University of Michigan press, 1975.

[52] Huberman, B.A., and Glance, N.S.: "Evolutionary games and computer simulations," Proceedings of the National Academy of Sciences, PNAS, vol.90, no.16, pp.7716-7718, 1993. 
[53] Iba, H., and Noman, N.: "New Frontiers in Evolutionary Algorithms: Theory and Applications," ISBN-10:1848166818, World Scientific Publishing Company, 2011.

[54] Iba, H.: "Evolutionary Approach to Machine Learning and Deep Neural Networks: Neuro-Evolution and Gene," ISBN-10:9811301999, Springer, 2018.

[55] Ichinose, G., and Masuda, N., "Zero-determinant strategies in finitely repeated games," Journal of Theoretical Biology, vol.438, pp.61-77, 2018.

[56] Inglett, J.E., and Rodriguez-Seda, E.J., "Object Transportation by Cooperative Robots," in Proc. SoutheastCon 2017, Charlotte, NC, pp. 1-6, 2017.

[57] Ishibuchi, H., Tsukamoto, N., and Nojima, Y., "Evolutionary many-objective optimization: A short review," in Proc. IEEE Congress on Evolutionary Computation, pp. 2419-2426, 2008.

[58] Karaboga, D., and Basturk, B.: "A powerful and efficient algorithm for numerical function optimization: Artificial Bee Colony (ABC) algorithm," Journal of Global Optimization, vol.39, pp.459-471, 2007.

[59] Karaboga, D., Gorkemli, B., Ozturk. C., and Karaboga, N.: "A Comprehensive Survey: Artificial Bee Colony (ABC) Algorithm and Applications," Artificial Intelligence Review, Doi:10.1007/s10462-012-9328-0, 2012.

[60] Kendall, G., Yao, X., and Chong, S.-Y.: “The Iterated Prisoners' Dilemma: 20 Years on,” World Scientific Pub Co Inc., 2007.

[61] Kenrick, D.T., Sex Murder and the Meaning of Life: A Psychologist Investigates How Evolution Cognition and Complexity are Revolutionizing our View of Human Nature, Basic Books, 2011.

[62] Kennedy, J., and Eberhart, R.C.: "Particle swarm optimization," Proceedings of IEEE the International Conference on Neural Networks, pp.1942-1948, 1995.

[63] Kennedy, J., and Eberhart, R.C.: "Swarm Intelligence," Morgan Kaufmann Publishers, 2001.

[64] Kondo, S., and Asai, R., "A reaction diffusion wave on the skin of the marine angelfish Pomacanthus," Nature, vol.376, pp.765-?768, 1995.

[65] Kusch, I., and Markus, M.: "Mollusc Shell pigmentation: Cellular automaton simulations and evidence for undecidability," Journal of theoretical biology, vol.178, pp.333-340, 1996. 
[66] Landaez, Y., Dohi, H., and Iba, H., "Swarm Intelligence for Object Retrieval Applying Cooperative Transportation in Unknown Environments," in Proc. 2018 4th International Conference on Robotics and Artificial Intelligence (ICRAI 2018), 2018.

[67] Levesque, H.J., "Is it enough to get the behaviour right?," Proc. of 21st Joint Conference on Artificial Intelligence (IJCAI-09), pp.1439-1444, 2009.

[68] Levitt, S.D., and Dubner, S.J., Freakonomics - A Rogue Economist Explores The Hidden Side Of Everything, William Morrow/Harper-collin, 2005.

[69] Li, A., and Yong, X., "Entanglement Guarantees Emergence of Cooperation in Quantum Prisoner's Dilemma Games on Networks," doi:10.1038/srep06286 Scientific Reports 4, Article number: 6286, 2014.

[70] Lohmann, R., "Structure evolution and incomplete induction," in Proc. 2nd Parallel Problem Solving from Nature (PPSN92), pp.175-185, NorthHolland, 1992.

[71] Martinez, G.J.: "Introduction to Rule 110," Rule 110 Winter WorkShop, 2004 http://www.rule110.org/amhso/results/rule110-intro/introRule110.html

[72] Melo, R.S., Macharet, D.G., and Campos, M.F.M., "Multi-object Transportation Using a Mobile Robot," in Proc. 12th Latin American Robotics Symposium and 3rd Brazilian Symposium on Robotics (LARS-SBR), pp.234-239, 2015.

[73] Mesoudi, A., Cultural Evolution: How Darwinian Theory Can Explain Human Culture and Synthesize the Social Sciences, University of Chicago Press, 2011

[74] Michalewics, Z., Genetic Algorithms + Data Structures = Evolution Programs, Springer-Verlag, 1992.

[75] Mitchell, M.: "Life and evolution in computers," History and Philosophy of the Life Sciences vol.23, pp.361-383, 2001.

[76] Mitchell, M.: "Complexity: A Guided Tour," Oxford University Press, 2009.

[77] Mochizuki, A., "Pattern formation of the cone mosaic in the zebrafish retina: a cell rearrangement model," J. Theor. Biol., vol.215, no.3, pp.345-61, 2002.

[78] Murray, J.D., Mathematical Biology: I. An Introduction, Springer, 3rd printing 2008 .

[79] Murray, J.D., Mathematical Biology II: Spatial Models and Biomedical Applications, Springer, 3rd printing 2008. 
[80] Nagel, K., and Shreckenberg, M.: “A cellular automaton model for freeway traffic," Journal de Physique I, vol.2, no.12, pp.2221-2229, 1992.

[81] Nakagaki, T., Yamada, H., and Toth, A., "Intelligence: Maze-Solving by an Amoeboid Organism," Nature, vol.407, p.470, 2000.

[82] Neary, T., and Woods, D.: "P-completeness of cellular automaton Rule 110," Proceedings of ICALP 2006 - International Colloquium on Automata Languages and Programming, Lecture Notes in Computer Science, vol.4051, pp.132-143, Springer, 2006.

[83] Ninagawa, S.: "1/f noise in elementary cellular automaton rule 110," Proceedings of the 5th international conference on Unconventional Computation, UC06, Lecture Notes in Computer Science, vol.4135/2006, pp.207-216, Springer, 2006.

[84] Nolfi, S., and Floreano, D. Evolutionary Robotics, MIT Press, 2000.

[85] Nowak, M.A.: "Evolutionary Dynamics: Exploring the Equations of Life," Belknap Press of Harvard University Press , 2006.

[86] Onuma, H., Okubo, A., Yokokawa, M., Endo, M., Kurihashi, A., and Sawahata, H., "Rebirth of a Dead Belousov-Zhabotinsky Oscillator," The Journal of Physical Chemistry A, vol.115, no.49, pp14137-14142, 2011.

[87] Parkinson, R., "The Dvorak Simplified Keyboard: Forty years of Frustration," Computers and Automation magazine, vol.21, pp.18-25, November, 1972.

[88] Penrose, R., The Emperor's New Mind: Concerning Computers, Minds, and The Laws of Physics, Pxford Univ Press, 1989.

[89] Penrose, R., "Beyond the doubting of a shadow a reply to commentaries on shadows of the mind," PSYCHE: An Interdisciplinary Journal of Research On Consciousness, vol.2, no.23, 1996.

[90] Pinker, S., How the Mind Works, W.W.Norton \& Co.Inc., 1991.

[91] Pinker, S., The Blank Slate: The Modern Denial of Human Nature, Penguin Books, 2003.

[92] Pinker, S., The Language Instinct: How The Mind Creates Language, Harper Perennial Modern Classics, 2007.

[93] Pinker, S., The Better Angels of Our Nature: Why Violence Has Declined, Penguin Books, 2012.

[94] Pinto, A., Oates, J., Grutter, A., and Bshary, R., "Cleaner wrasses Labroides dimidiatus are more cooperative in the presence of an audience," Current Biology, vol.21, no.13, pp.1140-1144, 2011. 
[95] Press, W.H., and Dyson, F.J., "Iterated Prisoner's Dilemma contains strategies that dominate any evolutionary opponent," PNAS: Proceedings of the National Academy of Sciences, vol.109, no.26, pp.10409-10413, 2012.

[96] Rajewsky, N., Santen, L., Schadschneider, A., and Schreckenberg, M.: "The asymmetric exclusion process: Comparison of update procedures," Journal of Statistical Physics, vol.92, pp.151-194, 1998.

[97] Rechenberg, I., "Evolution strategy and human decision making," Human decision making and manual control, Willumeit, H. P. (ed.), pp.349-359, NorthHolland, 1986.

[98] Reynolds, C.W.: "Flocks, herds and schools: A distributed behavioral model," Computer Graphics, vol.21, no.4, pp.25-34, 1987.

[99] Ridley, M., The Agile Gene: How Nature Turns on Nurture, Harper Perennial, 2004.

[100] Ridley, M., "The Evolution of Everything: How New Ideas Emerge,” Harper, 2015.

[101] Robbins, C., and Morrell, J., Mold, Housing and Wood, Western Wood Products Association, 2002.

[102] Rucker, R.: “Artificial Life Lab,” Waite Group Press, 1993.

[103] Sadhu, A.K., Rakshit, P., and Konar, A., "A modified Imperialist Competitive Algorithm for multi-robot stick-carrying application," Robotics and Autonomous Systems, vol.76, pp.15-35, 2015.

[104] Sandel, M.: “Justice: What's the Right Thing to Do?” Penguin, 2010.

[105] Schaffer, J.D., and Grefenstette, J.J., "Multi-Objective Learning via Genetic Algorithms," in Proc. of the 9th International Joint Conference on Artificial Intelligence, pp.593-595, 1985.

[106] Schaffer, J.D., "Multiple Objective Optimization with Vector Evaluated Genetic Algorithms," in Proc. of an International Conference on Genetic Algorithms and Their Applications, pp.93-100, 1985.

[107] Schelling, T.C.: "Dynamic models of segregation," Journal of Mathematical Sociology, vol.1., pp.143-186, 1971.

[108] Schwefel, H., Numerical optimization of computer models, John Wiley \& Sons, 1981.

[109] Segerstrale, U., Defenders of the Truth: The Sociobiology Debate, Oxford Univ Press, 2001. 
[110] Shayestegan, M., and Marhaban, M.H., "A Braitenberg Approach to Mobile Robot Navigation in Unknown Environments," in Ponnambalam, S.G., Parkkinen, J., Ramanathan, K.C. (eds.), Trends in Intelligent Robotics, Automation, and Manufacturing. IRAM 2012, Communications in Computer and Information Science, vol 330. Springer, 2012.

[111] Smith, J.M., and Szathmary, E., "The Origins of Life: From the Birth of Life to the Origin of Language," Oxford University Press, 2000.

[112] Sörensen, K., "Metaheuristics-the metaphor exposed," International Transactions in Operational Research, vol.22, no.1, pp.3-18, 2015.

[113] Sörensen, K., Sevaux, M., and Glover, F., “A History of Metaheuristics," arXiv:1704.00853v1 [cs.AI] 4 Apr 2017, to appear in Mart,R., Pardalos,P., and Resende,M., Handbook of Heuristics, Springer.

[114] Stewart, I., The Mathematics of Life, Basic Books, 2013.

[115] Tamura, H., "A comparison of line thinning algorithms from digital geometry viewpoint," in Proc. Int. Joint Conf. on Pattern Recognition, Kyoto, Japan, pp.715-719, 1978.

[116] Tero, A., Takagi, S., Saigusa, T., Ito, K., Bebber, D.P., Fricker, M.D., Yumiki, K., Kobayashi, R., and Nakagaki, T., "Rules for Biologically Inspired Adaptive Network Design,” Science, vol.327, no.5964, pp.439-442, 2010.

[117] Torabi, S., "Collective Transportation of Objects by a Swarm of Robots," Master Thesis in Complex Adaptative Systems, Chalmers University of Technology, 2015.

[118] Uchiyama, N., Mori, A., Kajita, Y., Sano, S., and Takagi, S., "Objecttransportation control for a human-operated robotic manipulator," in Proc. 2008 IEEE International Conference on Emerging Technologies and Factory Automation, pp.164-169, 2008.

[119] Vukov, J., Szabó, G., and Szolnoki, A., "Evolutionary prisoner's dilemma game on Newman-Watts networks,” Phys. Rev.E, vol.77, pp.026109-, 2008.

[120] Wang, Y., and de Silva, C.W., "An object transportation system with multiple robots and machine learning," in Proc. of the 2005 American Control Conference, pp.1371-1376, 2005.

[121] Weyland, D., "A critical analysis of the harmony search algorithm? How not to solve sudoku," Operations Research Perspectives, vol.2, pp.97-105, 2015.

[122] Weyland, D., "A Rigorous Analysis of the Harmony Search Algorithm - How the Research Community can be misled by a "novel" Methodology," International Journal of Applied Metaheuristic Computing, vol.1, no.2, pp.50-60, 2010. 
[123] Wilson, E.O., The Insect Societies, Belknap Press of Harvard University Press, 1971.

[124] Wilson, E.O., Sociobiology: The Abridged Edition Abridged Edition, Belknap Press of Harvard University Press, 1980.

[125] Witten, T.A., and Sander, L.M., "Diffusion-limited aggregation, a kinetic critical phenomenon," Phys. Rev. Lett., vol.47, pp.1400-1403, 1981.

[126] Wolfram, S.: “A New Kind of Science,” Wolfram Media, 2002.

[127] Yamashita, A., Fukuchi, M., Ota, J., Arai, T., and Asama, H., "Motion planning for cooperative transportation of a large object by multiple mobile robots in a 3D environment," in Proc. 2000 ICRA Millennium Conference, IEEE International Conference on Robotics and Automation, pp.3144-3151, 2000.

[128] Yang, X.-S., and Deb, S., 2009. "Cuckoo search via Levy flights," in Proc. World Congress on Nature \& Biologically Inspired Computing (NaBIC 2009), pp.210-214, IEEE Publications, 2009.

[129] Yang, X., Nature-Inspired Metaheuristic Algorithms, 2nd ed., Luniver Press, 2010. 